\title{
As fases históricas do debate sobre a transformação dos valores em preços de produção
}

\author{
TIAGO CAMARINHA LOPES*
}

The historical phases of the debate on the transformation of values into production prices. Even though the transformation problem in general does not have a widen accepted solution, it is possible to recognize scientific progress when the historical phases of the debate are put side by side in order to complement each other. Therefore, the debate originated from the challenge of the conciliation of the law of value with an equal average rate of profit, though sometimes said to be unfruitful by economists, shows evolution in the long run because it forces non-marxist economic schools to confront concretely the quality side of value in theory and to develop abstract models of planned economy in practice.

Keywords: value and price; transformation problem; labor theory of value, plan and market.

JEL Classification: B12; B24; B51.

\section{INTRODUÇÃO}

O problema da transformação dos valores em preços de produção é um dos temas teóricos mais controversos da disciplina de Economia Política do século XX. A não existência de uma solução aceita de forma unânime no início do século XXI assegura a complexidade do problema. Comum é ouvir que a discussão não apresenta resultados satisfatórios e sofre, portanto, de circularidade. Em oposição a essa visão, este artigo apresenta as fases históricas desse debate enfatizando que ele

\footnotetext{
* Mestrando em economia, IEUFU — Instituto de Economia da Universidade Federal de Uberlândia, MG, Brasil. Agradeço ao professor Bertram Schefold da Universidade de Frankfurt a.M. pela orientação inicial no tema e aos pareceristas anônimos pelas sugestões na forma de apresentação. Todo texto é de minha responsabilidade. E-mail: tiagocamarinhalopes@gmail.com. Submetido: 20/Julho/2009; Aprovado: $16 /$ Setembro/2010.
} 
atravessa progresso científico quando se considera seu desenvolvimento no longo prazo.

O objetivo principal deste texto é diferenciar o problema da transformação tradicional da problemática maior, na qual ele está inserido. Assim, ao se constatar que a abordagem tradicional é apenas um episódio específico já superado, o progresso do debate ficará claro. Para fundamentar esta tese, serão verificados três conceitos: a definição do problema da transformação, o caráter da crítica à economia marxista e o objeto de estudo da discussão. Caso estes conceitos tenham sofrido mudanças positivas nos últimos 125 anos e elas sejam justificadas, o avanço paulatino do debate terá sido demonstrado.

Para a análise adequada do desenvolver histórico do problema, é necessário partir de uma apresentação a mais abrangente possível. Dessa maneira, o problema da transformação descreve, em primeiro lugar, a relação entre valor e preço. Enquanto a palavra "valor" é uma categoria teórica nas ciências econômicas, que está em um nível relativamente alto de abstração, a expressão "preço" está mais próxima da realidade concreta da economia. Assim, tanto "valor" como "preço" designam as relações de troca das mercadorias - o valor, em nível teórico e o preço, em nível empírico $^{1}$. A passagem do abstrato para o concreto que se dá nos três volumes do Capital ocorre portanto em paralelo com a transformação dos valores em preços, e na tendência ideal, em preços de produção. O ponto de partida da discussão é a seguinte pergunta: Como se forma uma taxa média igual de lucro fundamentando-se na lei do valor? Dois principais métodos de atacar o problema surgiram após a formulação deste que pode ser chamado "desafio" de Engels (1885).

$O$ primeiro baseia-se na tese da contradição entre o primeiro e o terceiro volume do Capital, representada por Eugen von Böhm-Bawerk (1896). Ela incorpora uma crítica negativa à economia de Marx porque a nega por completo como teoria científica que possa explicar o modo de produção capitalista. A solução do problema, de acordo com essa linha, é impossível.

O segundo método de tratar do assunto remonta à aproximação de Ladislaus von Bortkiewicz (1907). Em oposição à negação fundamental, esse caminho tenta seguir com a própria estrutura contida no Capital através de formalização e especificação da apresentação. Ele possibilita um estudo mais detalhado da obra e incorpora dessa maneira a continuação da discussão sobre o mistério da taxa média igual de lucro sem a intenção de abandonar a teoria marxista. No decorrer do século XX surgem diferentes estudos sobre a matéria que seguem essa linha.

O ressurgimento do tema se deve à obra de Piero Sraffa (1960). Apesar de ter sido escrita com o propósito de criticar a escola neoclássica, descobriu-se rapidamente que a reabilitação da Economia Política Clássica, como Meek (1961) sintetizou a chegada de Sraffa ao debate, obrigatoriamente levava as ciências econômicas a enfrentar Marx. No entanto, a utilização do modelo de Sraffa para solucionar o problema da transformação teve um resultado contraditório: a própria questão

\footnotetext{
${ }^{1}$ Essa concepção parece ser o ponto de partida para Marx segundo Rojas (1989).
} 
havia se dissolvido. Nesse momento, a tese da redundância da teoria do valor trabalho, já antecipada por Engels no prefácio do livro III do Capital, foi confirmada e aceita de maneira bastante abrangente. Por isso, tentou-se encerrar o debate. Surpreendentemente, o assunto continuou sob uma nova forma, onde novas abordagens foram desenvolvidas, sobretudo com ênfase no aspecto qualitativo do conceito de valor.

O fato de a discussão ser longa e não possuir uma resposta clara indica que é necessário organizá-la historicamente para que as posições e controvérsias possam ser identificadas. Os obstáculos originados da falta de uma visão macro do debate são apontados por Schefold (1979), ao estressar a incompreensão geral sobre a relação entre Marx e Sraffa e a dificuldade de explicá-la após o uso do sistema sraffiano para a conversão de valores em preços de produção². Belluzzo (1998), por sua vez, avança justamente nesse sentido, com a pretensão de "contribuir para o esclarecimento dos pontos desta divergência”. A divisão em fases facilita a visualização do desenvolvimento das teses centrais e expõe de forma clara a repercussão da obra de Sraffa (1960) sobre o problema, contribuindo assim para uma apresentação totalizante do assunto.

O artigo descreve a formação histórica do problema da transformação dos valores em preços de produção com as seguintes seções além desta introdução: $O$ desafio de Engels representa o começo formal do debate, O problema da transformação tradicional descreve a repercussão que seguiu da correção de Bortkiewicz e a seção seguinte, $A$ crítica da redundância, apresenta alternativas contemporâneas de tratar do assunto. Um resumo gráfico seguido de uma conclusão intitulada $O$ progresso do debate fecha o artigo.

\section{O DESAFIO DE ENGELS}

Aparentemente o início da história do debate sobre a passagem dos valores a preços de produção é a correção feita por Bortkiewicz (1907) de um eventual equívoco de Marx (1894) no capítulo nove. Na verdade, a matéria começa mais cedo, formalmente com a publicação do livro II do Capital.

No condizente prefácio, Engels coloca a contradição da Economia Clássica como um desafio aos economistas teóricos da época. Ele consiste na demonstração de "como, não só sem ferir a lei do valor, mas, ao contrário, fundamentando-se nela, se pode e se deve formar uma taxa média igual de lucro". Apesar de Marx (1894) ter a pretensão de responder ao desafio, sua publicação não conseguiu es-

\footnotetext{
2 Schefold (1979) salienta que o distanciamento entre Marx e Sraffa devido ao problema da transformação leva ao estudo da forma do valor. Nos anos iniciais do debate sobre a teoria do valor desencadeado por Sraffa, Schefold manteve uma posição de conectar as duas teorias (marxista e sraffiana), mas acabou abandonando essa linha devido à forte estrutura formal da aproximação sraffiana. Sobre a influência de Marx sobre Sraffa, ver Bellofiore (2008).
} 
clarecer o problema, como o decorrente aparecimento de soluções alternativas demonstra.

Aqui, vale atentar primeiramente para o comentário de Engels no prefácio do livro III sobre a resposta de Lexis (1895), devido à antecipação da crítica da redundância que se estabeleceu mais de meio século mais tarde. Segundo Engels, Wilhelm Lexis escreve que a solução só seria possível se, para o tratamento da mercadoria individual, a medição do valor quanto tempo de trabalho fosse abandonada, pois desse ponto de vista parece que a relação entre o tempo de trabalho incorporado e o preço é arbitrária ${ }^{3}$. O valor parece não estar conectado com o preço de forma compreensível, o que possibilitaria a medição do preço com outra medida que não o tempo de trabalho ${ }^{4}$. No entanto, Lexis é muito cuidadoso em suas conclusões: ele não diz que os preços não podem ser medidos e explicados pelo tempo de trabalho. Ele acerta escrevendo que as unidades de trabalho incorporadas podem ser pensadas como sendo o ponto de partida de um deslocamento que leva para os preços reais. Essa observação é muito interessante, pois alude à função implícita da teoria do valor-trabalho na determinação das relações de troca. Os preços podem ser compreendidos como a forma de aparição do valor-trabalho, mas nada obriga a utilização deste ponto de vista. Por esse motivo, Engels (1894) descreve Lexis como um "marxista disfarçado de economista vulgar".

Engels passa então a aludir ao fato de como a teoria de Marx e a economia dominante descrevem exatamente a mesma realidade, só que com argumentações diferentes. A tese da redundância, aqui inconscientemente defendida por Lexis, é respondida por Engels ao comparar as explicações concorrentes do lucro. Como um dos objetivos do livro III era fazer a teoria de Marx comparável com as demais teorias econômicas, parece que esse anseio foi atingido. Pode-se portanto suspeitar de que a tese da desnecessidade da análise feita no livro I do Capital é a conclusão esperada a que chegariam economistas desinteressados na forma valor quando estudassem a obra magna de Karl Marx.

Excetuando a posição de Lexis, os demais participantes avançaram analiticamente sobre o problema da contradição. Resumidamente, a forma de resolver a questão na época era a descrição da operação da lei do valor em conjunto com o processo de concorrência. A discussão girava em torno da compreensão do fato de que a lei domina o movimento dos preços e cada participante do debate tentava

\footnotetext{
${ }^{3}$ Esse tipo de argumentação apontado por Lexis é antecipado por Marx no início do livro I. Lá ele adverte que a relação de troca entre dois valores de uso parece não ter nenhuma ligação com o tempo de trabalho, sendo uma relação aparentemente aleatória: "O valor de troca aparece, de início, como a relação quantitativa, a proporção na qual valores de uso de uma espécie se trocam contra valores de uso de outra espécie, uma relação que muda constantemente no tempo e no espaço. O valor de troca parece, portanto, algo casual e puramente relativo [...]” (Marx, 1867, p. 46).

${ }^{4}$ Por isso há a tendência de abandonar o sistema de valores. Assim preparou-se Marx para a subsequente crítica (contradição). Mas esse não é o motivo, na fase mais nova, pelo qual o sistema de valores deva ser deixado. Atualmente, a teoria do valor trabalho deveria ser posta de lado não porque contradiz o sistema de preços, mas porque é redundante para sua determinação.
} 
ligar o conceito da teoria valor-trabalho com a taxa de lucro média. Esta teoria, sendo amplamente aceita no final do século XIX, não precisava ser primeiramente justificada, de modo que a discussão visava compreender a teoria do valor de Marx a partir de David Ricardo. Assim, a continuidade entre a Economia Política Clássica e sua crítica permeia a problemática da ligação entre valores e preços desde sua formulação original. Com efeito, sem a demonstração de que a teoria do valor-trabalho tem uma base real e que os preços são, na realidade, expressões do tempo de trabalho, a questão da transformação pode ser muito bem concebida como um “falso problema”, na expressão popularizada por Samuelson (1971) . Engels (1895-1896), na tentativa de solucionar o desentendimento vigente, quis demonstrar a existência da lei do valor com a contraditória "interpretação histórica" do Capital. Apesar de para ele a exposição de Marx ser a única correta, havia grande pressão por um esclarecimento da questão depois da publicação do livro III. A formulação do processo econômico real de nivelação da taxa de lucro baseado na teoria do valor-trabalho contida ali não se diferenciava substancialmente das concorrentes soluções propostas, de modo que mesmo o livro final do Capital ficou devendo a resposta ao desafio.

Os críticos, segundo Engels, ficaram assim ao mesmo tempo desapontados e satisfeitos. Por isso, para ele, a diferença em relação a David Ricardo deveria ser explicitamente mostrada, quanto à determinação da grandeza do valor. Essa diferença específica seria a "melhoria técnica" da teoria ricardiana do valor-trabalho, não fazendo parte da Crítica da Economia Política no sentido mais profundo, qualitativo. Isso mostra que existe uma continuidade importante entre a Economia Clássica e a contribuição de Marx.

Engels (1895-1896) escreve que os economistas, quando falam de valor, falam do valor que se estabelece efetivamente na troca. Marx, por sua vez, quando usa o termo "valor", quer dizer frequentemente valor individual, uma grandeza que não se define só no processo de circulação, mas já na produção. No contexto da transformação, a relação entre a esfera da produção e da circulação é fonte de desentendimento. Como Antônio de Paula (2000) lembra acertadamente, somente a compreensão dialética dos dois ramos pode esclarecer como se determina a grandeza do valor de troca efetivo. A conexão entre valor individual e valor social ocorre justamente em paralelo com a ligação da produção com a circulação e estressa a diferença entre a teoria de valor de Marx da de David Ricardo. Assim, a teoria marxista do valor tem suas raízes nas formulações de Ricardo e é, no sentido estritamente quantitativo, apenas uma melhora técnica. O objeto de estudo seria primeiramente a quantidade de valor, e como na economia política clássica, valor só pode ser expressão de tempo de trabalho, a questão do esclarecimento da taxa de lucro média igual com base na lei do valor está posta por Marx de forma sólida. A parte quantitativa do problema da transformação é vista como solucionada somen-

\footnotetext{
${ }^{5}$ A posição de Samuelson já estava encaminhada antes mesmo do choque de Sraffa. Ver Samuelson (1957).
} 
te na fase após Sraffa (1960), e por isso a terceira fase tem uma forma bem diferente desta primeira: pergunta-se sobre o conteúdo dessa quantidade.

Sabe-se que a questão da qualidade foi posta e resolvida por Marx no primeiro livro do Capital. Essa questão é, de certo modo, a singularidade da crítica da economia política: por que a medida de valor é expressão do tempo de trabalho? Nota-se que ela tem uma forma muito similar ao problema que surge com a solução quantitativa do problema da transformação após o "choque de Sraffa": o trabalho não pode ter uma função diferenciada quando se trata da economia somente em sua estrutura de valor de uso. Justamente por esse motivo, o problema da transformação se desenvolve necessariamente em direção à análise qualitativa da teoria do valor.

Assim, o cerne da primeira fase eram descrições não formalizadas de como o funcionamento da lei do valor explica a formação da taxa média de lucro igual. A posição oposta à escola marxista ${ }^{6}$ defendia a tese de que havia uma contradição insolúvel entre o sistema de valores desenvolvido no livro I com o sistema de preços apresentado no livro III, enquanto a crítica da redundância ${ }^{7}$, não conseguindo se estabelecer, teve de ser postergada. Ademais, uma conclusão definitiva não foi formulada. O debate continuou, portanto, e modificou-se após a alteração de Bortkiewicz (1907). Foi dessa maneira que surgiu uma segunda fase, o problema da transformação propriamente dito, como ficou em âmbito mundial definitivamente conhecido.

\section{O PROBLEMA DA TRANSFORMAÇÃO TRADICIONAL}

Partindo de Ricardo, Marx tenta superar a dificuldade mencionada da Economia Política Clássica por meio da ilustração de que a lei do valor domina o movimento dos preços. Isso significa que, mesmo que os preços não sejam diretamente proporcionais às quantidades de trabalho, existe um mecanismo que explica esse desvio. Em sua tentativa, porém, de formular uma expressão matemática que descrevesse o processo, Marx não conseguiu apresentar uma formalização completa do que ele apresenta em forma de texto. Como Heinrich (1999) aponta, desde então o problema não é mais visto como uma falha da Economia Política Clássica, mas sim como uma do próprio Marx.

A forma de transformação apresentada por Marx no capítulo nove do livro III está baseada na contabilização dos preços de custo em termos de valor. Esta suposição garante que os capitalistas podem comprar as mercadorias referentes ao capital constante e variável pelos seus valores individuais. Apesar deste caso ser possível (por exemplo, se a composição orgânica dos respectivos setores produtores dos insumos em questão fossem exatamente iguais à composição orgânica média da economia), de modo geral, os preços das mercadorias que compõem o capital

\footnotetext{
${ }^{6}$ Representada principalmente por Eugen von Böhm-Bawerk (1896).

${ }^{7}$ Representada implicitamente por Wilhelm Lexis (1895).
} 
constante e o variável também vão se diferenciar dos seus valores individuais. Marx (1894) reconhece, e avisa, que uma formalização ideal deveria levar isso em conta.

O método quantitativo da transformação precisaria assim ser modificado por completo, de modo que o procedimento inclua todos os casos possíveis de composição orgânica. Seguindo Tugan-Baranowsky e provavelmente influenciado por Wolfgang Mühlpfordt, Ladislaus von Bortkiewicz apresenta uma solução de enorme repercussão que tenta superar essa restrição ${ }^{8}$.

A contribuição de Bortkiewitz (1907) marca o ponto de partida para a busca de um algoritmo de conversão dos valores em preços de produção e por isso os artigos que o seguem tem o lado puramente quantitativo como objeto de estudo. O debate é nessa fase, portanto, visivelmente menos ideológico e polarizado. Ademais, não houve durante essa etapa nenhuma linha de continuidade significativa. Esse é o principal motivo pelo qual o problema da transformação pareceu ser circular. Apenas um ponto unia os participantes nesse período: o problema existe. Se ele foi artificialmente criado pela modificação de Bortkiewitz, se surgiu do próprio equívoco de Marx, ou se é produto da teoria ricardiana do valor, importava pouco. Fato é que a questão se disseminou especificamente nesse contexto, o que contribuiu para que o problema da transformação fosse frequentemente identificado com a conversão puramente quantitativa de um sistema para outro.

O específico deste episódio é que ele tem uma conclusão amplamente aceita possibilitada pela publicação da obra de Sraffa (1960) que pode ser resumida assim: O sistema dos valores se diferencia do sistema de preços de produção. Essa diferença se deve aos critérios de distribuição da mais-valia. No sistema de valores, o critério é o tamanho do capital variável (a mais-valia está distribuída em proporção à grandeza do trabalho vivo de cada setor), enquanto no sistema de preços de produção a soma de capital variável com capital constante serve como critério de distribuição. A passagem de um sistema para outro é a chamada transformação de valores em preços de produção. Dessa maneira, a transformação é possível via multiplicação do sistema de valores com uma matriz específica que reorganiza a distribuição da mais-valia de modo que surjam os preços de produção e a taxa de lucro proporcional ao tamanho do capital, independentemente de como ele é distribuído entre capital variável e constante. O inverso de tal matriz possibilita, a

\footnotetext{
${ }^{8}$ A referência a Bortkiewicz (1907) como o iniciador do problema da transformação tradicional tem de ser mantida porque quase todos autores da época entraram na discussão devido a sua correção. Mühlpfodt (1893) teria conseguido, na verdade, antes da publicação do livro III do Capital encontrar uma solução para a charada da taxa de lucro média igual e ela seria, segundo Quaas (1992), idêntica ao método do modelo de Sraffa com excedente e com a suposição de que o salário (salário participante no excedente) é igual a zero. Além de Tugan-Baranowski e Mühlpfordt, o economista V.K. Dmitriev e o matemático Georg von Charassof participaram da formalização da teoria do valor-trabalho no início do século XX. Enquanto Dmitriev ganhou popularidade na época da controvérsia de Cambridge-Cambridge, o potencial prematuro de Charassof só foi reconhecido recentemente. Sobre a origem do problema da transformação tradicional ver Howard e King (1992), Quaas (1992) e Schefold (2004). Em notas não voltadas para publicação, Sraffa criticou frontalmente o método de solução empregado por Bortkiewicz. Sobre isso, ver Gehrke e Kurz (2006).
} 
propósito, a transformação inversa, ou seja, de preços de produção em valores. Isso significa que há uma relação quantitativa de determinação mútua entre os sistemas. Essa conclusão não causa mais discórdias. Por outro lado, as discussões sobre o significado ou interpretação de tal transformação parecem não terminar ${ }^{9}$.

Foi então que, quando Samuelson apresentou o "algoritmo-borracha" com seu sintetizador "voilà" em 1971, teve início uma controvérsia de caráter novo ${ }^{10}$. Curiosamente, Samuelson passou a ser atacado tanto pelo lado marxista, fiel à teoria do valor-trabalho, como pelo lado contrário, disposto a enterrar a abordagem da criação de valor via labor.

Lerner (1972), por exemplo, criticou Samuelson porque ele daria permissões ilegais à teoria do valor-trabalho. Para ele, a teoria seria reutilizável se fosse descrita apenas como redundante. É revelador como o aflito de Lerner ante as concessões de Samuelson à teoria econômica de Marx mostra a superação da crítica da linha Böhm-Bawerk: se antes a teoria marxista do valor era rejeitada devido a um erro, agora ela passa a ser logicamente aceitável. O nível da crítica foi portanto rebaixado, evidenciando o avanço do desenvolvimento da teoria do Capital.

Outra reação a Samuelson (1971) foi Southworth (1972), que procura os motivos para o então crescente interesse sobre Marx por parte dos economistas e a razão de sua dificuldade em entendê-lo. Parte da confusão seria causada pelo próprio texto de Marx, enquanto outra parte seria resultado da diferença de método científico. Southworth lança a pergunta, perspicaz no contexto do "disfarce de economista vulgar" renovado por Samuelson, sobre até que ponto essa dificuldade com Marx seria uma manobra consciente. Por causa da crescente atenção que a teoria marxista recebe, surgiriam, segundo Southworth, artigos que têm o único propósito de contrabalancear tal movimento. O "voilà" de Samuelson seria um exemplo desses artigos, assim como sua empreitada de desqualificar Marx como um ricardiano menor.

No debate sobre o problema da transformação, ter elucidado que os valores podem ser convertidos em preços de produção, e vice-versa, considera Samuelson como sua verdadeira contribuição. Assim, com base em uma transformação analítica correta, passa a ser possível construir argumentos a partir dos dois extremos, tanto a partir dos valores como a partir dos preços de produção. Conhecidamente, a análise do valor é tida como um caminho desnecessário, por outro lado, o nível de preços isolado dos valores é visto como uma instituição sem sentido. A polarização do debate ficou portanto bastante visível depois da conclusão do problema da transformação tradicional.

Mas, como Samuelson se locomove somente dentro desta fase do problema da transformação, fica evidente por que ele pede pelo fim do debate. Quando

\footnotetext{
${ }^{9}$ Para um resumo formal do resultado de Sraffa (1960) sobre a transformação ver, por exemplo, Pasinetti (1979).

${ }^{10}$ A controvérsia entre marxistas e sraffianos aguçou-se a partir de então. Um estudo desta disputa foi feito por Fees-Dörr (1989).
} 
Luciano Coutinho (1974) reagiu enfatizando que Samuelson não utilizava o método dialético e por isso estaria incapacitado de abordar todos os lados da questão, não estava claro que o debate de então era uma fase específica, estritamente preocupada com o lado quantitativo. Samuelson se protegia com a definição restringida do problema da transformação, evitando a análise do valor. $\mathrm{O}$ algoritmo tinha sido encontrado, o problema da transformação, solucionado (ou extinto). Mas, ainda assim, artigos sobre o tema continuavam a ser publicados. Por quê? Porque no decorrer da discussão perdeu-se a origem do desafio, de modo que a formulação qualitativa de Marx saiu do centro da questão. Assim, quando uma solução foi encontrada, o problema não era mais contemplado em sua totalidade.

O fluxo natural do debate deveria ser portanto de retornar às origens da problemática. E foi exatamente o que ocorreu. O artigo de Baumol (1974) simboliza a ascensão de uma nova maneira de encarar o problema da transformação. Para ele, os autores desde Bortkiewicz deram muita atenção a um tema que, para Marx, era periférico. "O que Marx realmente quis dizer", como intitulou essa contribuição, é que a distribuição da mais-valia em diferentes formas de renda do capital através da concorrência pode ser exemplificada por um modelo matemático. A busca por esse modelo matemático tinha, desde 1907, tomado todo o esforço dos participantes, mas o que realmente importava era saber como a mais-valia era distribuída na prática. Além de remeter à intenção original da operação, Baumol (1974) lembra que Marx sabia que os preços de produção poderiam ser quantitativamente determinados sem a análise da forma do valor do livro I, e que por isso o movimento crucial do problema não seria a conversão dos valores em preços de produção, mas sim o da "transformação" da mais-valia nas categorias de renda como lucros e juros. Essa concepção do problema difere substancialmente da definição clássica, a da transformação quantitativa.

Desde o momento em que uma operação de conversão matemática correta foi aceita em larga escala, o modo de tratar o problema começou a mudar. A partir daí, o que surge na literatura são estudos que procuram o significado da transformação. Em 1977, Ian Steedman publicou o livro intitulado Marx after Sraffa, desafiando os economistas a mostrarem a necessidade e praticidade da teoria do valor trabalho para a análise materialista da economia, o que marcou o início de uma nova fase.

Isso evidencia que a abordagem do problema da transformação tradicional foi apenas um episódio específico inserido em uma questão abrangente que envolve a continuação da Economia Política em Marx. O resultado prático da solução do problema da transformação tradicional, que emana em conjunto com a solução do problema quantitativo e expõe o progresso científico da discussão, é a refutação definitiva da crítica da contradição entre os livros I e III do Capital formulada por Böhm-Bawerk (1896). Foi nesse contexto que a crítica da contradição foi integralmente substituída pela crítica da redundância. 


\section{A CRÍTICA DA REDUNDÂNCIA}

Diferentes alternativas surgiram como resposta ao "choque de Sraffa" para tratar da redundância da análise dos valores. O tratamento de cunho sraffiano da passagem de valores a preços causou uma controvérsia em torno da teoria do valor-trabalho de tal forma que mesmo os economistas de tendência marxista começaram a abandoná-la. Desde então, reina discordância sobre como confrontar essa situação. Por isso, a terceira fase do debate sobre o problema da transformação é em primeiro lugar uma disputa entre teóricos da teoria do valor-trabalho. Esse também é o motivo pelo qual a comunicação com posições não marxistas ficou limitada nos últimos anos. A incerteza sobre a função da teoria do valor passou a ser o tema principal e o ponto de partida para tratar do tema acabou se tornando a procura por um sentido econômico da conversão de valores em preços de produção. Entre as alternativas que se encaixam nesse novo cenário estão: a "Nova Solução", o Sistema Único Temporal, o desenvolvimento qualitativo e a aproximação probabilística ${ }^{11}$.

\section{A “Nova Solução”}

A primeira solução alternativa de maior ressonância foi a chamada "New Solution" ou "New Interpretation". Lipietz (1982) pode ser considerado o responsável pela popularização dessa nova interpretação. Duncan Foley (1982) e Duménil (1983-1984) foram aqueles que organizaram as bases dessa corrente.

Duménil (1983-1984) tenta moldar o início da nova interpretação explicitando o conteúdo do debate nessa fase. O que para ele está em questão é a relevância da teoria do valor-trabalho. Segundo Duménil, o conceito de valor seria uma necessidade teórica, pois a agregação dos diferentes valores de uso precisa da redução (mesmo que inconsciente) a um terceiro em comum. Já a teoria do valor-trabalho teria uma função esclarecedora específica que precisaria ser mostrada: enquanto a teoria do valor-trabalho explica a divisão social do trabalho em um contexto histórico, a teoria do preço só pode explicá-la em sociedades que produzem mercadorias. Além disso, a "Nova Solução" deveria ser defendida com citações de Marx, ou seja, ela não deve ser expandida sem pontos de apoio nas formulações do $\mathrm{Ca}$ pital. Por fim, a interpretação tradicional (que leva à redundância), reconhece Duménil (1983-1984), segue também da argumentação de Marx. Isso significa que a desnecessidade da teoria do valor-trabalho pode ser demonstrada com o próprio Capital. Isso remete a ambivalências no texto de Marx que deveriam ser analisadas com cuidado.

Apesar de esses pontos organizarem a aproximação, não é possível reconhecer uma contracrítica concreta ao ataque da redundância nesse estágio. Mesmo que a

\footnotetext{
${ }^{11}$ Esta é uma seleção representativa de reações que visa ilustrar a diversidade de interpretações para o "choque de Sraffa".
} 
"New Interpretation" tenha sido a alternativa mais popular entre teóricos do valor-trabalho ${ }^{12}$, ela é criticada e vista com receio nos últimos anos. De um lado a "New Solution" é etiquetada como neoricardiana e rejeitada ${ }^{13}$, por outro lado diferentes autores se mostram simpáticos a ela quanto ao seu objetivo de desafiar a dominância da solução neoricardiana do problema da transformação ${ }^{14}$. A "Nova Solução" foi por isso pioneira no sentido político e agregador, mas sua proposta teórica frágil não teve continuidade.

\section{O "desenvolvimento qualitativo"}

Já a aproximação “desenvolvimento qualitativo" foi bastante influenciada pelos trabalhos pioneiros de Isaak Rubin (1927). Os autores desta tradição exaltam a análise qualitativa do valor, a fim de resolver o impasse. Neste sentido, o conceito de trabalho abstrato é estudado com maior atenção, de tal maneira que a qualidade do valor toma o centro das atenções em detrimento da análise sobre a determinação de sua grandeza. Ademais, essa linha de estudo foca diretamente as questões sobre a ruptura de Marx com a Economia Política Clássica.

A partir de uma leitura cuidadosa do Capital, seria possível reconhecer diferentes níveis de argumentação onde as categorias "valor", "preço" e "trabalho" seriam passo a passo trabalhadas, do abstrato ao concreto. A ligação entre valor e preço seria assim um desenvolvimento categórico, uma conexão entre categorias de diferentes níveis de abstração e não um processo lógico-matemático. Converter matematicamente valores em preços de produção não seria o modo correto de abordar a questão. Por que então teria Marx aludido a tal processo? Heinrich procura superar essa dificuldade com sua tese de que "Marx, com efeito, abre um novo terreno de conhecimento, mas que o discurso da economia clássica se repete em diversos pontos dentro de sua própria argumentação" (Heinrich, 1999, p. 17, tradução minha). Isso significa que, apesar de Marx iniciar a Crítica da Economia Política e inaugurar um novo objeto de estudo, ele ainda utilizaria conceitos clássicos que seriam incompatíveis com a nova ciência. Apesar de Heinrich ser a favor de um desenvolvimento qualitativo entre valor e preço, ele explicita acertadamente que Marx, no livro III, estava particularmente interessado na ligação quantitativa entre as duas categorias. A conexão qualitativa estaria, com a obra de Marx, terminada, mas a quantitativa não. Assim, Heinrich (1999) se distancia corretamente de Baumol (1974), que deu a entender que Marx tinha um interesse pequeno pelo lado quantitativo do problema. Heinrich aceita, portanto, a crítica da redundância quando se trata exclusivamente da determinação da quantidade de valor.

Já Belluzzo (1998), embora não aponte como Heinrich para eventuais "restos ricardianos" em Marx, enfatiza da mesma maneira a necessidade de reexaminar as

\footnotetext{
${ }^{12}$ Glick e Ehrbar (1987) e Campbell (1997) são exemplos para a aceitação da "New Interpretation".

${ }^{13}$ Por exemplo por Sinha (1997).

${ }^{14}$ Por exemplo: Moseley (2000); Fine, Lapavitsas e Saad-Filho (2004) e Gontijo (2006).
} 
relações entre a Economia Política e sua Crítica através de cuidadoso estudo da transformação que a teoria do valor sofre quando passa de Ricardo para Marx. Ele eleva portanto a questão da ruptura e evita a questão quantitativa ao afirmar que a conversão de valores em preços de produção é uma forma de "eludir a questão e não de resolvê-la" (Belluzzo, 1998, p. 136).

O problema da transformação tradicional é assim, dentro dessa linha de pesquisa, evitado através de um forte apelo para o tratamento qualitativo da questão. De modo geral, este tipo de abordagem tende a identificar todo elemento genuíno da Economia Política Clássica presente em Marx como um "erro", como se não existisse nenhum componente adequado na análise de Adam Smith e David Ricardo que devesse ser mantido. $\mathrm{O}$ estudo das contribuições históricas indica que é improvável que essa interpretação consiga colocar um ponto final na discussão, a não ser que a interpretação da solução quantitativa seja incorporada ao projeto de estudo e se admita que Marx estava, corretamente, de fato interessado em uma solução quantitativa.

\section{O “Sistema Único Temporal”}

Uma outra corrente, que vem sendo chamada de "Sistema Único Temporal"15, inicia-se, segundo Antonio de Paula (2000), também na década de 1980, mas com menor popularidade. Ela se apresenta como alternativa a todos métodos que ligam os valores aos preços de forma simultânea, ou seja, aos métodos da linha "Dmitriev, Bortkiewicz, Sweezy, Seton, Okishio, Morishima, Shaikh, Steedman, e Laibman", de acordo com Freeman, Kliman e Wells (2004).

A interpretação simultânea, aqui sob crítica, parte do pressuposto de que a transformação não ocorre em etapas: o sistema de valores e o sistema de preços de produção são determinados ao mesmo tempo. Existem assim dois "sets" de relações de trocas. Uma conclusão conhecida dessa interpretação é a possibilidade de se optar por um dos sistemas, de modo que não haja ligação teórica entre eles ${ }^{16}$. Segundo Freeman, Kliman e Wells (2004), isso levou à separação dos sistemas e provocou a procura pelo sentido da transformação. Os representantes da conversão temporal argumentam que a linha de pesquisa da transformação simultânea desemboca necessariamente em conclusões da escola sraffiana. A transformação sem consideração de lapso temporal leva obrigatoriamente à formação de teorias do tipo "Surplus Approach" na explicação do excedente e por isso a teoria do valor-trabalho aparece, nestes casos, necessariamente como redundante.

No Sistema Único Temporal, ao contrário, a transformação acontece em uma linha cronológica. Primeiramente tem-se o sistema de valores, que é determinado pelas condições técnicas da economia e, em segundo lugar, o sistema de preços, que é derivado dessa origem. Assim surge uma devida conexão econômico-temporal entre os dois sistemas, de modo similar à ideia de Marx. Além disso, a suposição de

\footnotetext{
${ }^{15}$ Neto (1997) trata especificamente desta alternativa.

${ }^{16}$ Essa conclusão é em Samuelson (1971) a mais explícita.
} 
uma taxa de lucro igual é criticada e é afirmado que ela só pode ser pensada em tendência ${ }^{17}$. Neste sentido, o Sistema Único Temporal tem o objetivo de colocar a própria solução de Marx em discussão para esclarecer o sentido da transformação. Ela refuta portanto a correção de Bortkiewicz com a afirmação de que, desde então, esta interpretação errônea dominou o debate. Como outros críticos de Bortkiewicz também utilizam o método simultâneo da transformação, o ataque da corrente Sistema Único Temporal é bem abrangente: ele atinge desde neoricardianos até os seguidores da "Nova Interpretação". O Sistema Único Temporal é resumidamente uma tentativa de expandir o debate de tal forma que toda interpretação sobre a questão possa ser discutida de igual para igual. Por essa razão, o método de etapas de Marx não poderia ser excluído da discussão e deveria ser levado em consideração.

Os críticos do Sistema Único Temporal, por sua vez, veem nele mais uma tentativa frustrada de "salvar Marx". De fato, os representantes do Sistema Único Temporal poderiam ser mais diretos sobre o motivo pelo qual eles negam o resultado da redundância, como opina também Gary Mongiovi (2002).

\section{O método probabilístico de modelagem do mercado}

Dentre todas essas alternativas, o método probabilístico merece destaque porque respondeu ao desafio de Steedman (1977) de forma mais direta. Farjoun e Machover (1983) desenvolveram uma aproximação estatística para verificar postulados da teoria de Economia Política a fim de resolver o impasse do problema da transformação. Para eles, um pressuposto fundamental do problema é ao mesmo tempo um errôneo: o pressuposto da taxa igual de lucro. Eles criticam o determinismo que surge dessa suposição e apresentam um modelo não determinista, onde a taxa de lucro só pode ser dada em termos probabilísticos. Os autores salientam que os métodos tradicionais consideram as taxas de lucro dos setores iguais porque a concorrência e a igualação das taxas dos setores são uma experiência real, de modo que essa tendência aparece como estado verdadeiro para o teórico. $\mathrm{Na}$ verdade, as taxas de lucro são diferentes, como seus resultados empíricos mostram e os analistas práticos sabem. Apesar de Marx também estar ciente disso, no seu procedimento de cálculo dos preços de produção, ele trata as taxas de lucro como se tivessem realmente se igualado ${ }^{18}$. Por outro lado, Marx foi muito claro que o equilíbrio é um estado que nunca acontece de verdade e só pode ser imaginado em tendência. Resumidamente, esse modelo pode ser formulado da seguinte maneira: ${ }^{19}$

\footnotetext{
${ }^{17}$ Essa conclusão está bem próxima da principal ressalva de Farjoun e Machover (1983). Ambos os métodos são temporais em oposição ao tradicional método simultâneo.

${ }^{18}$ O problema de observar a taxa de lucro média igual como "real” está na inversão da transformação. Os valores podem assim ser deduzidos dos preços. Marx advertiu que a suposição da taxa média de lucro igual poderia levar a essa conclusão errada e por isso salientou que, mesmo quando a suposição for feita, somente uma direção da transformação pode ter sentido, que é de valores para preços.

${ }^{19} \mathrm{O}$ objetivo aqui é explicitar o método probabilístico como forma de resolução da controvérsia do "choque de Sraffa". A apresentação do modelo é feita com forte base em minha interpretação da questão.
} 
As relações de troca no mercado são ajustadas aos preços de produção através do processo de mercado livre. O preço de mercado de uma mercadoria pode ser livremente determinado entre o comprador e o vendedor, de modo que os participantes do mercado tratam os preços como variáveis que são limitadas por parâmetros desconhecidos. Os preços de produção não são o objeto de estudo nessa aproximação, em oposição a Sraffa: só existem o sistema de valores (os valores individuais da produção) e os preços de mercado (as relações de troca observáveis que se formam no mercado). Como Marx escreve, essas últimas relações de troca estão sujeitas a leis econômicas: em última instância a lei do valor. Isso significa que, apesar de os preços de mercado serem "abertos", a lei do valor os domina e os regula. A ligação entre valor e preço pode então ser modelada com cálculos probabilísticos onde não há uma tendência absoluta para o equilíbrio, ao contrário do método tradicional, onde a troca pelos valores equivale a um equilíbrio de mercado.

De valores para preços de produção (e vice-versa)

e de valores para preços de mercado

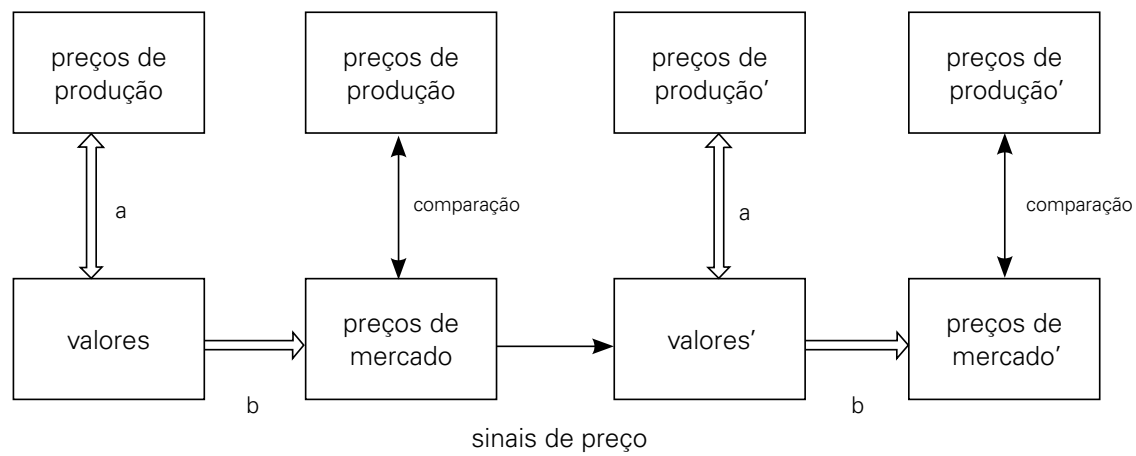

$\begin{array}{llll}\text { Produção } & \text { Circulação } & \text { Produção } & \text { Circulação }\end{array}$

A figura resume o método probabilístico, que concretiza o movimento da lei do valor e mostra porque é ela que resolve o enigma da taxa média de lucro igual. Com o modelo de Farjoun e Machover, é possível considerar o algoritmo tradicional mas não é necessário substituí-lo. A transformação tradicional ganha, na verdade, um novo significado ao lado do método não determinista. O ponto de partida dessa apresentação é o sistema de valores, o retângulo denominado "valores". Estes são os valores individuais das mercadorias, eles são em outras palavras os tempos individuais utilizados para produzir cada produto individual. Esse sistema apresenta a realidade técnica da produção e é, em sociedades que socializam o trabalho individual através do mercado, informação inacessível sem ele. Ele é determinado pela própria estrutura técnica da economia. Sabidamente, essa constelação de valores não possibilita na realidade a taxa de lucro geral igual, como Marx enfatiza em várias passagens.

A solução tradicional está representada pela seta dupla "a": ela é um algoritmo 
que possibilita a nova distribuição da mais-valia de acordo com a taxa geral de lucro igual. Com isso, a taxa de lucro no sentido de Sraffa e os preços de produção são determinados pela própria estrutura de valores-de-uso da produção. Essa solução tradicional incorpora a descrição formal do movimento real e deve ser interpretada com cuidado: como existe uma concordância entre os dois lados, é por exemplo dito que os valores não são o ponto de partida dos preços de produção ${ }^{20}$. Como a circulação ainda não entrou em cena aqui, fica claro que nesse estágio não se trata do "tempo de trabalho socialmente necessário".

A alternativa " $b$ " esclarece o que Marx tentava mostrar na totalidade de sua apresentação. O ajustamento dos valores aos preços de produção ocorre através da repetição do processo de mercado, onde os preços de produção e a taxa geral de lucro só podem ser uma criação abstrata, um objetivo em torno do qual a produção se orienta. A transformação " $b$ " parte do sistema de valores (estrutura de valor-de-uso, estado técnico da economia) para o sistema de preços de mercado com um cálculo não determinista. Os preços de mercado são por sua vez o único acesso à realidade técnica da produção, dito de outra forma: as condições técnicas de produção só se mostram através do processo de "tâtonnement" do mercado. Os dados da produção (a quantidade de inputs, inclusive trabalho) são propriedade privada no modo de produção capitalista e só são socializados no comércio. Apesar desses dados existirem, eles seriam sem o mercado somente acessíveis através de estatização elou planejamento ${ }^{21}$. Por isso, os preços de mercado agem como informação empírica sobre as condições técnicas de produção. Assim, tanto "valor" como "preço" designam as relações de troca das mercadorias — o valor, em nível teórico, e o preço, em nível empírico. Nesta aproximação, os valores não são somente teoricamente prioritários aos preços, mas também temporalmente, como Marx argumenta. Bettelheim (1969) salienta que as diferenças entre as "teorias dos preços" e os conceitos teóricos de Marx não se manifestam no nível prático de cálculo econômico, o que sustenta parcialmente a tese de que teorias econômicas não marxistas fornecem indiretamente material técnico para a prática do planejamento ${ }^{22}$.

A relação entre "a" e "b" fica clara com a passagem do sistema de preços de produção para a esfera da circulação: “a” seria a transformação em nível teórico, representando o algoritmo de conversão abstrato que representa o resultado da concorrência. Este é o foco da fase do "problema da transformação tradicional"; "b" por sua vez seria a transformação mais próxima do concreto, a que acontece de fato via troca das mercadorias.

\footnotetext{
${ }^{20}$ Esse é o ponto de partida para a formalização da crítica da redundância, como o fez Paul A. Samuelson.

${ }^{21}$ Essa é a razão pela qual escolas econômicas não marxistas são direcionadas a construir modelos de economia planificada ao tratarem do problema da transformação.

${ }^{22}$ Essa é, aliás, a posição de Oskar Lange no debate sobre o Cálculo Econômico.
} 
Os preços de produção representam o objetivo do movimento e o pressuposto para a taxa geral de lucro igual: depois dos preços de mercado terem se formado na circulação, o sistema de preços de mercado é comparado com o sistema de preços de produção. Caso eles estejam diferentes, então não foi atingida uma taxa de lucro igual para os setores. Esse é o motivo de uma nova alocação dos fatores no próximo período. O sistema de valores irá se transformar então no novo sistema (valores). Essa comparação e alocação constante se expressa na importância dos sinais de preços ou na relação entre oferta e demanda.

Dessa maneira o encontro entre o debate sobre o cálculo econômico e a operação da lei do valor na economia planificada com a discussão sobre o problema da transformação tradicional fica apontado como possível prosseguimento do debate.

\section{RESUMO GRÁFICO}

O seguinte quadro ilustra as fases históricas do debate sobre o problema da transformação dos valores em preços de produção. Sua disposição não significa que os temas sejam claramente separados, mas apenas que cada etapa tem uma característica mais marcante. O progresso do debate total pode ser reconhecido quando se analisam as fases, não em sentido cronológico apenas, mas também como conjuntos complementares. A passagem da crítica da forma "contradição" para "redundância" significa que o debate produziu uma descoberta genuína após vários anos de embates.

As fases históricas do debate sobre a transformação dos valores em preços de produção

\begin{tabular}{|c|c|c|c|}
\hline & $\begin{array}{c}\text { Fase 1: } \\
\text { O desafio de Engels } \\
(1885-1906)\end{array}$ & $\begin{array}{c}\text { Fase 2: } \\
\text { O Problema daTransformação } \\
\text { Tradicional } \\
(1906-1971)\end{array}$ & $\begin{array}{c}\text { Fase 3: } \\
\text { A crítica da redundância } \\
(1971-\text { hoje })\end{array}$ \\
\hline Tema Principal & $\begin{array}{l}\text { Lei do Valor e Taxa } \\
\text { Média Igual de Lucro }\end{array}$ & $\begin{array}{c}\text { Fórmula Matemática } \\
\text { para transformação }\end{array}$ & $\begin{array}{c}\text { Teoria do } \\
\text { Valor-Trabalho }\end{array}$ \\
\hline Crítica & $\begin{array}{l}\text { Contradição entre o } \\
\text { sistema de valores e o } \\
\text { sistema de preços }\end{array}$ & $\begin{array}{c}\text { Solução quantitativa de Marx, } \\
\text { identidades } \\
\sum \text { valores }=\Sigma \text { preços } \\
\sum \text { mais-valia }=\sum \text { lucros }\end{array}$ & $\begin{array}{l}\text { Redundância do } \\
\text { sistema de valores }\end{array}$ \\
\hline $\begin{array}{l}\text { Função da } \\
\text { Transformação }\end{array}$ & $\begin{array}{l}\text { Nivelação das taxas } \\
\text { de lucro com base } \\
\text { na Lei do Valor }\end{array}$ & $\begin{array}{l}\text { Conversão dos valores } \\
\text { em preços de produção }\end{array}$ & $\begin{array}{l}\text { Distribuição da } \\
\text { mais-valia / simulação } \\
\text { do mercado }\end{array}$ \\
\hline $\begin{array}{l}\text { Ponto de } \\
\text { Partida }\end{array}$ & Desafio de Engels & $\begin{array}{l}\text { Formalização de Marx } \\
\text { incompleta }\end{array}$ & $\begin{array}{l}\text { Relação entre a } \\
\text { transformação e } \\
\text { planejamento }\end{array}$ \\
\hline
\end{tabular}




\begin{tabular}{|c|c|c|c|}
\hline Efeito de Sraffa* & $\begin{array}{l}\text { Diferença entre } \\
\text { Marx e Economia Política } \\
\text { Clássica aumenta }\end{array}$ & Término & $\begin{array}{c}\text { Confirmação da redundância } \\
\text { quantitativa da Teoria } \\
\text { do Valor-Trabalho }\end{array}$ \\
\hline Conclusão & - & $\begin{array}{c}\text { Contradição entre o sistema de } \\
\text { valores e o sistema de preços } \\
\text { explicada (problema quantitativo } \\
\text { solucionado) }\end{array}$ & - \\
\hline $\begin{array}{l}\text { Próximas } \\
\text { Pesquisas }^{* *}\end{array}$ & $\begin{array}{l}\text { Relação entre Marx } \\
\text { e escolas Sraffiana e } \\
\text { Neoricardiana }\end{array}$ & - & $\begin{array}{l}\text { Função/Origem/ } \\
\text { Utilidade da Teoria } \\
\text { do Valor-Trabalho }\end{array}$ \\
\hline $\begin{array}{l}\text { Enunciado } \\
\text { Formal }^{* * *}\end{array}$ & $\begin{array}{c}\text { Como se forma uma } \\
\text { taxa média de lucro igual } \\
\text { fundamentando-se na lei } \\
\text { do valor? }\end{array}$ & $\begin{array}{l}\text { Como é possível modelar a } \\
\text { transação do sistema de valores } \\
\text { para o sistema de preços? }\end{array}$ & - \\
\hline
\end{tabular}

\section{O PROGRESSO DO DEBATE}

De acordo com o presente estudo, o problema da transformação tradicional está inserido em uma problemática maior, que envolve as questões de continuidade e descontinuidade da Economia Política Clássica. Quanto aos três conceitos sob análise apresentados na introdução, são aos seguintes resultados a que se chega:

Primeiro, é necessário aumentar o escopo da definição da transformação dos valores em preços de produção, pois ele contém um campo de análise mais abrangente do que admitido. Por isso, a definição estrita do tema só faz sentido quando se trata de um período específico do debate. A concepção clássica do problema da transformação abrange apenas a fase do "problema da transformação tradicional", que lida exclusivamente com a questão quantitativa da conversão.

Segundo, ao longo do tempo a ênfase em determinados pontos da temática se altera. Principalmente, o caráter da crítica à economia marxista sofreu uma mudança significativa. Da perspectiva teórica, o progresso se expressa na falha da crítica da linha Böhm-Bawerk. Além disso, a mudança do argumento crítico contra

\footnotetext{
* O "Efeito de Sraffa" (ou choque de Sraffa) descreve qual foi a influência que a publicação de "Produção de Mercadorias por Meio de Mercadorias" teve em cada uma das fases. O efeito para a fase 2 foi o próprio término. Para a fase 3 foi a confirmação da tese da redundância da Teoria do Valor-Trabalho para a determinação do sistema de preços de produção. Na fase 1, a diferença entre Marx e os economistas clássicos passou a ser o foco.

*A linha "Próximas Pesquisas" mostra quais temas ganharam atenção após o término da fase 2.

:**:O "Enunciado Formal” caracteriza o ponto de partida "oficial” para o tratamento do problema da transformação. Para a fase 3, o enunciado ainda está para ser preenchido, porque o próprio problema ainda se apresenta para muitos como um "problema inexistente". A sugestão aqui proposta é a de que o enunciado formal da fase 3 esteja relacionado com o planejamento econômico, como está indicado na linha "Ponto de Partida".
} 
a teoria do valor de Marx de "contradição" para "redundância" implica que a rejeição da economia marxista é uma questão de decisão política e não técnica. Por essa razão o debate polarizou-se fortemente após Samuelson (1971).

Terceiro, a análise da forma do valor tornou-se o objeto de estudo no debate depois que o método matemático utilizado com base em Sraffa (1960) foi aceito por grande parte dos teóricos. Sendo assim, as antigas soluções quantitativas típicas do "problema da transformação tradicional" abrem espaço para a formulação de uma nova questão de natureza qualitativa. A partir desse ponto, como o conteúdo expresso nas relações quantitativas de troca após Sraffa passou a ser "vazio", o debate foi direcionado à questão qualitativa do valor.

Quanto a este último ponto, que talvez seja o mais frágil dos três, vale ainda uma última ressalva. A Crítica da Economia Política encontra, como Schefold (1974) tinha antecipado, resistência toda vez que os teóricos se veem impelidos a lidar com a questão do valor. A teoria econômica ortodoxa entrava sistematicamente o estudo sobre a qualidade do valor, dedicando-se exclusivamente ao seu lado quantitativo. Por isso, mesmo que a fase atual sobre o problema da transformação demande a análise da forma do valor, como argumentado, economistas distantes da tradição marxista vão refutá-la devido à sua inutilidade para a medição quantitativa da riqueza. É nesse contexto que se deve entender a formulação do conceito da redundância da teoria do valor-trabalho. Na virada para o século XXI não se pode ter uma discussão similar à da primeira fase, porque hoje a lei do valor não é aceita amplamente como objeto de estudo nas ciências econômicas. Ainda no final do século retrasado não havia grandes dúvidas de que o sistema dos valores-trabalho era o primórdio do sistema de preços, pois a teoria do valor-trabalho tinha uma aceitação muito maior antes da dissolução da escola ricardiana. Ademais, aceitando-se o desafio original de Engels, não se pode dizer que a tese da redundância é uma solução para o problema porque esse resultado não se fundamenta na lei do valor. Assim, a crítica da redundância seria somente uma resposta ao problema tradicional da transformação, de caráter estritamente quantitativo, o que estressa o caráter passageiro deste episódio.

Por outro lado, mesmo que escolas econômicas não marxistas desconsiderem a teoria do valor-trabalho, elas desenvolvem modelos abstratos de economia planificada ao conciliarem os dois sistemas e contribuem, ainda que inconscientemente, para melhor compreensão da economia capitalista e para o desenvolvimento da teoria da economia mista. Um dos resultados disso foi o desenvolvimento de aproximações que, em combinação com os modelos econômicos de insumo-produto, podem oferecer novas ferramentas para a prática do planejamento. ${ }^{23}$ Assim, como o problema quantitativo abstrato está solucionado, a problemática se volta necessariamente à Crítica da Economia Política devido à obrigatoriedade de se compreender o conceito de valor em Marx. Como este está ligado estreitamente com a categoria de trabalho abstrato, a discussão sobre o problema da transformação

${ }^{23}$ Uma apresentação geral sobre esse processo foi feita por Clark (1984). 
está fadada a culminar no estudo da formação histórica dessa categoria teórica, sem, no entanto, abandonar o aspecto de determinação quantitativa concreta dos preços. É assim que se cumpre o objetivo científico do economista de abordar dialeticamente a teoria do valor.

Sendo assim, mostra-se que, devido à mudança nos conceitos de definição do problema, do caráter da crítica e do objeto de estudo em direção à teoria do planejamento e à Crítica da Economia Política, existe progresso científico no debate. Nesse contexto, é possível lançar um olhar para o futuro e constatar que, ainda que de forma experimental e descoordenada, a discussão sobre o problema da transformação dos valores em preços de produção está se direcionando ao estudo da forma do valor e ao planejamento econômico possível dentro da sociedade capitalista.

\section{REFERÊNCIAS BIBLIOGRÁFICAS}

ANTÔNIO DE PAULA, J. (2000) “A dialética valores e preços”, Revista de Economia Política, 20(4): 116-136.

BAUMOL, W. J. (1974) “The transformation of values: What Marx "really" meant (an interpretation)",Journal of Economic Literature, 12(1): 51-62.

BELLOFIORE, R. (2008) "Sraffa after Marx: An open issue”, in Chiodi, G. e Ditta, L. E. (org.). Sraffa or an Alternative Economics. New York: Palgrave Macmillan, pp. 68-92.

BELLUZZO, L. G. (1998) Valor e Capitalismo: Um Ensaio sobre a Economia Política. Campinas: Unicamp, IE.

BETTELHEIM, C. (1969) A Transição para a Economia Socialista. Zahar: Rio de Janeiro.

BÖHM-BAWERK, E. von (1896 [2007]) Karl Marx and the Close of his System. Auburn, Alabama: Ludwig von Mises Institute.

BORTKIEWICZ, L. von (1907 [2007]) “On the correction of Marx's fundamental theoretical construction in the third volume of Capital”, in Sweezy, P. (org.). Karl Marx and the Close of his System by Eugen von Böhm-Bawerk \& Böhm-Bawerk's Criticism of Marx by Rudolf Hilferding. Auburn, Alabama: Ludwig von Mises Institute.

CAMPBELL, A. (1997) "The transformation problem: A simple presentation of the "new solution". Review of Radical Political Economics, 29(3): 59-69.

CLARK, D. L. (1984) "Planning and the real origins of input-output analysis", Journal of Contemporary Asia, 14(4): 408-429.

COUTINHO, L. (1974) “Notas sobre o problema da transformação: Uma crítica a Samuelson”, Estudos Cebrap, 9: 5-49.

DUMÉNIL, G. (1983-1984) "Beyond the transformation riddle: A labor theory of value”, Science and Society, XLVII(4): 427-450.

ENGELS, F. (1885 [1963]) “Vorwort: Das Kapital, Bd. II.”, in Karl Marx — Friedrich Engels — Werke, Band 24, [MEW 24] Dietz Verlag, Berlin/DDR, 1963. Prefácio de O Capital - Livro II”.

ENGELS, F. (1894 [2004]) "Vorwort: Das Kapital. Kritik der Politischen Ökonomie. Dritter Band. Hamburg 1894 “, in: Marx-Engels-Gesamtausgabe. Zweite Abteilung: "Das Kapital” und Vorarbeiten, Bd. 15. [MEGA, II, 15, Text], Berlin: Akademie Verlag, 2004, 5-23. Prefácio de O Capital - Livro III".

ENGELS, F. (1895-1896 [2003]) Wertgesetz und Profitrate. Erster Nachtrag zu Buch 3 des Kapitals in: Marx, K.; Engels, F. (1871-1895) Manuskripte und Redaktionelle Texte zum dritten Buch des 
“Kapitals”, [MEGA, II, 14, Text, 2003], Akademie Verlag 2003. Suplemento ao Livro Terceiro de O Capital (Lei do Valor e Taxa de Lucro).

FARJOUN, E. e MACHOVER, M. (1983) Laws of Chaos: A probabilistic approach to political economy. London: Verso Editions and NLB.

FEESS-DÖRR, E. (1989) Die Redundanz der Mehrwerttheorie: Ein Beitrag zur Kontroverse zwischen Marxisten und Neoricardianern. Marburg: Metropolis.

FINE, B., LAPAVITSAS, C. e SAAD-FILHO, A. (2004) "Transforming the transformation problem: Why the "new interpretation" is a wrong turning", Review of Radical Political Economics, 36(1): 3-19.

FOLEY, D. K. (1982) "The value of money the value of labor power and the Marxian transformation problem", Review of Radical Political Economics, 14(2): 37-47.

FREEMAN, A., KLIMAN, A e WELLS, A. (orgs.) (2004) The New Value Controversy and the Foundations of Economics. Londres: Edward Elgar Publishing.

GEHRKE, C. e KURZ, H. D. (2006) "Sraffa on von Bortkiewicz: Reconstructing the classical theory of value and distribution", History of Political Economy, 38(1): 91-149.

GLICK, M. e EHRBAR, H. (1987) “The transformation problem: An obituary”, Australian Economic Papers, 26 (December): 294-317.

GONTIJO, C. (2006) "A "nova solução" do problema da transformação de valores em preços e o Marxismo", EconomiA, Brasília (DF), 7(2): 225-248.

HEINRICH, M. (1999) Die Wissenschaft vom Wert. Münster: Dampfboot.

HOWARD, M. C. e KING, J. E. (1992) A History of Marxian Economics. London: Macmillan.

LERNER, A. (1972) “A note on 'understanding the Marxian notion of exploitation'”, Journal of Economic Literature, 10(1): 50-51.

LEXIS, W. (1895) “The concluding volume of Marx's Capital”, The Quarterly Journal of Economics, 10(1): $1-33$.

LIPIETZ, A. (1982) “The so-called “transformation problem” revisited”, Journal of Economic Theory, 26(1): 59-88.

MARX, K. (1867 [1985]) O Capital: crítica da economia política. Livro Primeiro: O Processo de Produção do Capital. São Paulo: Nova Cultural.

MARX, K. (1884/1885 [2005]) Das Kapital. Kritik der Politischen Ökonomie. Zweites Buch. Redaktionsmanuskript von Friedrich Engels, in Marx-Engels-Gesamtausgabe. Zweite Abteilung: "Das Kapital” und Vorarbeiten, Bd. 12. [MEGA, II, 12, Text, 2005], Akademie Verlag, 2005. O Capital - Livro II.

MARX, K. (1894 [2004]) Das Kapital. Kritik der Politischen Ökonomie. Dritter Band. Hamburg 1894 in Marx-Engels-Gesamtausgabe. Zweite Abteilung: „Das Kapital“ und Vorarbeiten, Bd. 15. [MEGA, II, 15, Text, 2004], Berlin: Akademie Verlag, 2004. O Capital - Livro III.

MEEK, R. (1961) “Mr. Sraffa's rehabilitation of classical economics”, Scottish Journal of Political Economy, 8(2): 119-136.

MONGIOVI, G. (2002) "Vulgar economy in Marxian garb: a critique of temporal single system Marxism", Review of Radical Political Economics, 34(4): 393-416.

MOSELEY, F. (2000) "The "New Solution" to the transformation problem: A sympathetic critique", Review of Radical Political Economics, 32(2): 282-316.

MÜHLPFORDT, W. (1893) Preis und Einkommen in der privatkapitalistischen Wirtschaft. Zugl. Diss. Königsberg.

NETO, João Machado Borges (1997) A transformação dos valores em preços de produção em um sistema único temporal. Dissertação de Mestrado, PUC-SP, 1997.

PASINETTI, L. (1979) Lectures on the Theory of Production. UK: Palgrave Macmillan.

QUAAS, F. (1992) Das Transformationsproblem: Ein theoretischer Beitrag zur Analyse der Quellen und Resultate seiner Diskussion. Marburg: Metropolis. 
ROJAS, R. (1989) Das unvollendete Projekt: zur Entstehungsgeschichte von Marx' “Kapital”. Berlin, Hamburg: Argument Verlag.

RUBIN, I. I. (1927 [1978]) “Abstract labour and value in Marx's system”. Capital \& Class, 5: 107-39.

SAMUELSON, P. A. (1957) "Wages and interest: a modern dissection of marxian economic models", American Economic Review, 47(6): 884-912.

SAMUELSON, P. A. (1971) "Understanding the Marxian notion of exploitation: a summary of the socalled transformation problem between Marxian values and competitive prices", Journal of Economic Literature, 9(2): 399-431.

SCHEFOLD, B. (1974) "Wert und Preis in der marxistischen und neokeynesianische Akkumulationstheorie", Mehrwert, 2: $125 \mathrm{ff}$.

SCHEFOLD, B. (1979) "Kapitaltheorie: Vom Transformationsproblem und der Kritik an der Neoklassik zur Rekonstruktion der Politischen Ökonomie”, Jahrbuch für Sozialwissenschaft, 30(2): 177 -188 .

SCHEFOLD, B. (2004) Einführung. Der Dritte Band: Herkunft und Wirkung in: Das Kapital. Kritik der politischen Ökonomie. Dritter Band. Hamburg 1894. Berlin: Akademie Verlag, 2004. MarxEngels-Gesamtausgabe. Zweite Abteilung: "Das Kapital” und Vorarbeiten, Bd. 15, [MEGA, II, 15, Apparat, 2004], 871-910. Apresentação de O Capital - Livro III” da MEGA, edição 2004.

SETON, F. (1957) “The 'transformation problem'”. The Review of Economic Studies, 24(3): 149-160.

SINHA, A. (1997) "The transformation problem: A critique of the "New Solution", Review of Radical Political Economics, 29(3): 51-58.

SOUTHWORTH, G. (1972) "Samuelson on Marx, A note". Review of Radical Political Economics, 4(5): 103-111.

SRAFFA, P. (1960) Production of Commodities by Means of Commodities: prelude to a critique of economic theory. Cambridge: Cambridge University Press.

STEEDMAN, I. (1977) Marx after Sraffa. London: New Left Books. 